\title{
Thermal behaviour of materials in interrupted phase change
}

\author{
Zoltán Andrássy ${ }^{1}$ (1) $\cdot$ Zoltán Szánthó $^{1}$
}

Received: 9 October 2018 / Accepted: 2 July 2019/Published online: 19 July 2019

(C) The Author(s) 2019

\begin{abstract}
The most critical part and barrier of phase change material (PCM) applications are the accuracy of simulations and the control of the process. The state of the PCM and the momentarily stored energy cannot be estimated easily unless numerous temperature sensors are used. There are a lot of models used by researchers, but most of them focus solely on the full charging or discharging of the PCM thermal energy storage. In a real working environment, the phase change is often interrupted so this phenomenon should also be modelled with high accuracy. The aim of this paper is to present the newly developed diagonal model validated by differential scanning calorimetry measurements, which can model what occurs inside the hysteresis of the solid-liquid two-phase state. The model was created and validated by using paraffin wax (P53) and was further tested with coconut oil (C.oil20), which has a very wide hysteresis. The modelling accuracy of the different models was compared with each other, and the evaluations were carried out.
\end{abstract}

Keywords Phase change materials (PCM) - Differential scanning calorimetry (DSC) - Enthalpy-temperature curves . Phase transition · Interrupted melting/solidification

\section{List of symbols}

c Specific heat capacity $\left(\mathrm{kJ} \mathrm{kg}^{-1} \mathrm{~K}^{-1}\right)$

$c_{\text {app }}$ Apparent heat capacity of the PCM during melting $\left(\mathrm{kJ} \mathrm{kg}^{-1} \mathrm{~K}^{-1}\right)$

$f \quad$ Liquid fraction of PCM (1)

$H \quad$ Enthalpy $\left(\mathrm{kJ} \mathrm{kg}^{-1}\right)$

$L_{\mathrm{f}} \quad$ Latent heat of fusion $\left(\mathrm{kJ} \mathrm{kg}^{-1}\right)$

$T$ Temperature $\left({ }^{\circ} \mathrm{C}\right)$

\section{Superscripts}

m Melting

$\mathrm{s}$ Solidification

c Corner/break point

$\begin{array}{ll}\text { Subscripts } & \\ 1 & \text { Liquid } \\ \mathrm{m} & \text { Melting } \\ \text { melting, range } & \text { Melting temperature range } \\ \mathrm{s} & \text { Solid } \\ \mathrm{x} & \text { Interruption point }\end{array}$

Zoltán Andrássy

andrassy@epget.bme.hu

1 Department of Building Services and Process Engineering, Budapest University of Technology and Economics, Müegyetem rakpart 3-9, Budapest 1111, Hungary

\section{Introduction}

Phase change materials (PCM) are widely used as thermal energy storage (TES) materials. As heat is stored through the phase change of materials and not through their temperature, it is possible to expand the commonly used TES solutions. PCM TES systems could be used for heating/cooling of residential or office buildings, industrial processes, renewable energy storages, cold chain management applications or consumer products to increase their energy efficiency or thermal comfort [1-9].

Researchers use different methods to model the thermal behaviour of PCMs [10-23]. Ideally, phase change occurs completely and that is why most researchers only investigate full cycles of phase change [8-13], but in practice a partial phase change frequently occurs. The solid-liquid two-phase state is investigated with the use of models inconsistent with each other $[24,25]$. Their accuracy has to be analysed, and a new, more accurate model should be established. Thermal calorimetry measurements are needed for the examination of the two-phase state.

Differential scanning calorimetry (DSC) was used to carry out temperature-heat capacity measurements. DSC is a thermoanalytical technique, where the difference in the amount of heat required to increase a unit of temperature of a sample and a reference is measured as a function of temperature [26-28]. The sample and the reference are 
kept on the same temperature during the measurement. The heat capacity in the function of reference temperature is well-known. The heat capacity of the sample is calculated from the difference of the values between the sample and the reference.

Based on the recommendations in the articles [26-33], every DSC measurement was carried out with $0.5 \mathrm{~K} \mathrm{~min}^{-1}$ heating/cooling rate, so thermal equilibrium was ensured and the temperature of the material sample was homogeneous and uniform. As a control, the result is investigated with three measurements carried out with $2 \mathrm{~K} \mathrm{~min}^{-1}$.

First, paraffin wax (P53) was measured and a model was developed to ensure an accurate simulation of phase change materials. To validate and to extend the applicability of the model, further tests were made with coconut oil (C.oil20), which has a very wide hysteresis.

Every measurement was carried out with three different samples, and three different cycles were measured in each sample. The presented results show the average of the most accurate series of data measured.

The properties of the analysed materials are presented in Table 1 without supercooling.

\section{Modelling the full phase change}

In this chapter, the existing thermal behaviour models are reviewed. The most commonly used techniques to model the thermal behaviour of PCMs are the effective heat capacity method [10-18] and the enthalpy method [18-23]. The effective heat capacity method considers the heat of fusion as heat capacity in the range of the phase change, and the effective heat capacity is defined as the slope of the enthalpy-temperature curve. The enthalpy method defines a continuous and reversible function for a given volume and material, which will return the temperature depending on the calculated enthalpy.

The most accurate model is the calorimetry measurement-based data modelling, where temperature-heat capacity (or enthalpy) pairs are given and the model uses interpolation to model the thermal behaviour of PCMs. With the purpose of simplification and also due to the limits of processor capacity, simplified models are used. The effect of hysteresis is neglected many times, and only

Table 1 Physical properties of the used PCMs

\begin{tabular}{lrl}
\hline Property & P53 & C.oil20 \\
\hline$T_{\mathrm{m}}$-melting temperature ${ }^{\circ} \mathrm{C}$ & 53.5 & 20 \\
$L_{\mathrm{f}}$ - heat of fusion $/ \mathrm{kJ} \mathrm{kg}^{-1}$ & 196.2 & 107.6 \\
$c_{\mathrm{s}}$ - - 0 olid specific heat capacity $/ \mathrm{kJ} \mathrm{kg}^{-1} \mathrm{~K}^{-1}$ & 4.1 & 1.8 \\
$c_{\mathrm{l}}$-liquid specific heat capacity $/ \mathrm{kJ} \mathrm{kg}^{-1} \mathrm{~K}^{-1}$ & 3.1 & 2.1 \\
\hline
\end{tabular}

the melting or solidification curve is used in both cases. For simplification, only the melting curve is shown in Models I-IV. These models only apply for materials with no supercooling.

- Model I: Effective heat capacity model with constant heat of fusion in the melting temperature range [10-15, 18, 29].

This model calculates the heat of fusion as specific heat in the range of the phase change. When the melting temperature is a single temperature and not a range [10], the heat of fusion follows a Dirac delta function (Fig. 1). When the melting temperature is defined as a range of temperature, Eq. (1) is used to determine the enthalpy in the melting region:

$c_{\text {melting, range }}=\frac{L_{\mathrm{f}}}{T_{1}^{\mathrm{m}}-T_{\mathrm{s}}^{\mathrm{m}}}+c_{\mathrm{app}}, \quad$ when $\quad T_{\mathrm{s}}^{\mathrm{m}}<T_{\mathrm{PCM}}<T_{1}^{\mathrm{m}}$

$c_{\text {app }}=(1-f) \cdot c_{\mathrm{s}}+f \cdot c_{1}$,

This model is shown in Fig. 1 for the P53 material. The four different dashed lines show examples for the different approaches of the model, for different temperature ranges according to equation (1):

- I/1 curve estimates the melting point as an exact temperature; in this case, it is $53.5^{\circ} \mathrm{C}$.

- $\mathrm{I} / 2$ curve models the heat of fusion with a $1{ }^{\circ} \mathrm{C}$ difference, $53-54{ }^{\circ} \mathrm{C}$.

- $\mathrm{I} / 3$ has a $3{ }^{\circ} \mathrm{C}$ difference, $52-55^{\circ} \mathrm{C}$.

- $\mathrm{I} / 4$ shows the heat of fusion when it is modelled in the full range of $6^{\circ} \mathrm{C}, 50.5-56.5^{\circ} \mathrm{C}$ [12].

The certainty of this model is based on the magnitude of the melting temperature range. The certainty of the model is higher when the modelled melting temperature range is closer to the measured range (Fig. $1 \mathrm{I} / 4$ curve).

- Model II: Effective heat capacity model using two lines [15-17].

In this model, two lines are fitted in the melting temperature range to get higher accuracy. These lines approximate the measured data on the temperature-effective heat capacity from two sides, presented in Fig. 2. The accuracy of the model is higher, but the computation demand is still low. The model uses two lines optimized for the temperature-effective heat capacity plane.

The model could be more accurate if there were more lines fitted in the melting range.

- Model III: Enthalpy method with interpolation [18-23].

This model is based on data obtained from calorimetry measurements. Temperature-heat capacity data pairs are measured, and interpolation is used to calculate the 

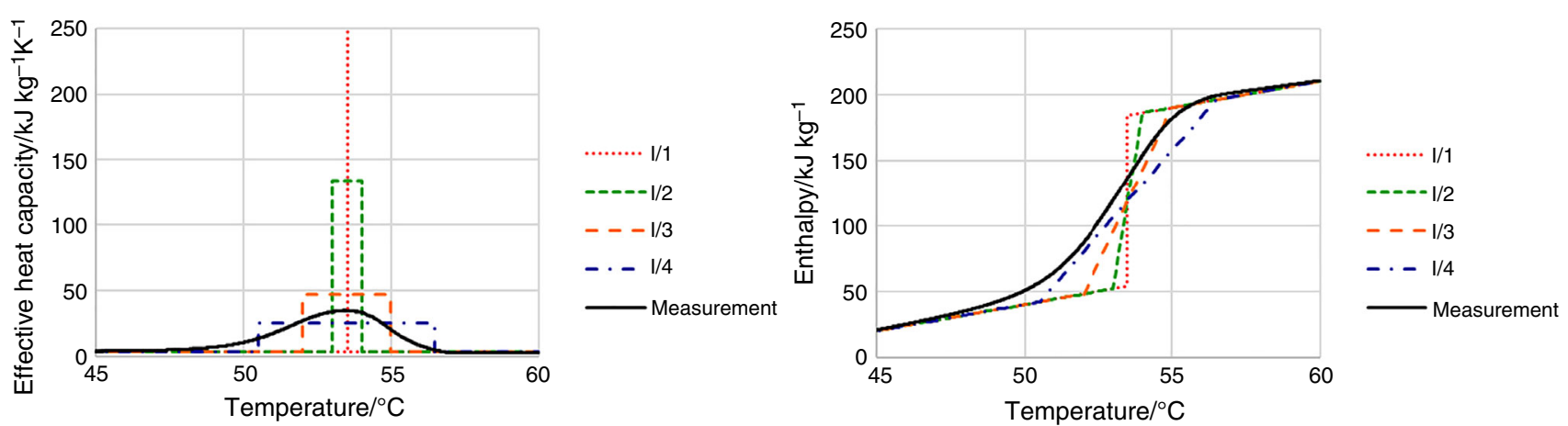

Fig. 1 Temperature-effective heat capacity and temperature-enthalpy curves for constant heat of fusion model when the temperature difference is considered $1{ }^{\circ} \mathrm{C}, 3{ }^{\circ} \mathrm{C}$ and $6{ }^{\circ} \mathrm{C}$ for the tested P53
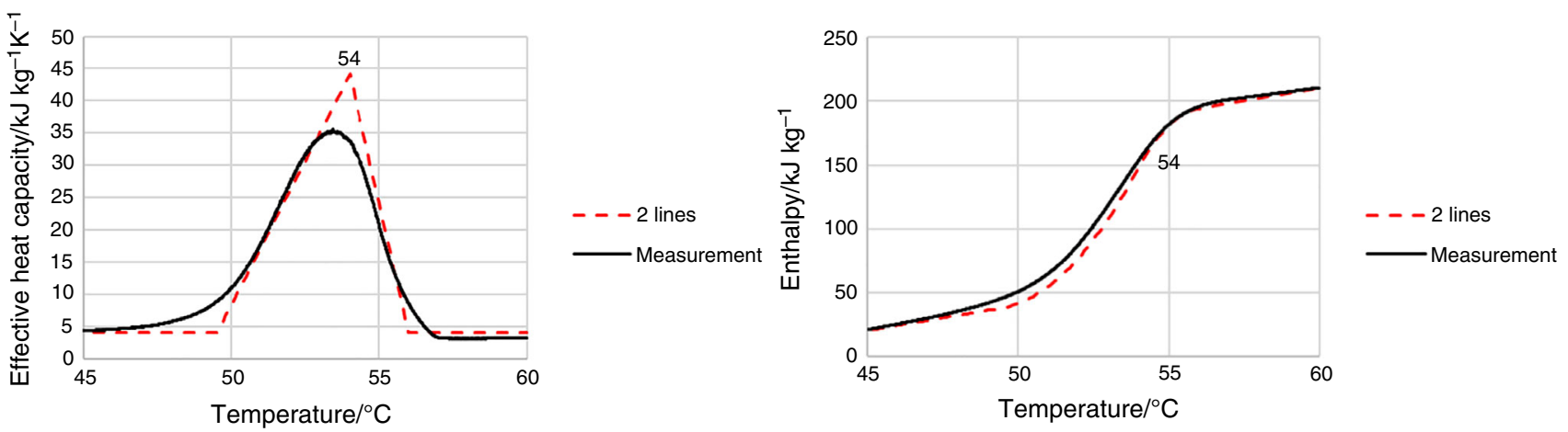

Fig. 2 Temperature-effective heat capacity and temperature-enthalpy lines using the two-line model for P53

enthalpy in the necessary temperature points. It has the highest certainty and, of course, the highest computation requirement to model the thermal behaviour of PCMs. Calorimetry measurement is also required. Higher certainty is accomplished with more data pairs and more precise measurements. An example is presented in Fig. 3.

- Model IV: Enthalpy method with fitted lines.

This method is based on Model III, but instead of interpolating with premeasured data pairs, fitted lines are used.

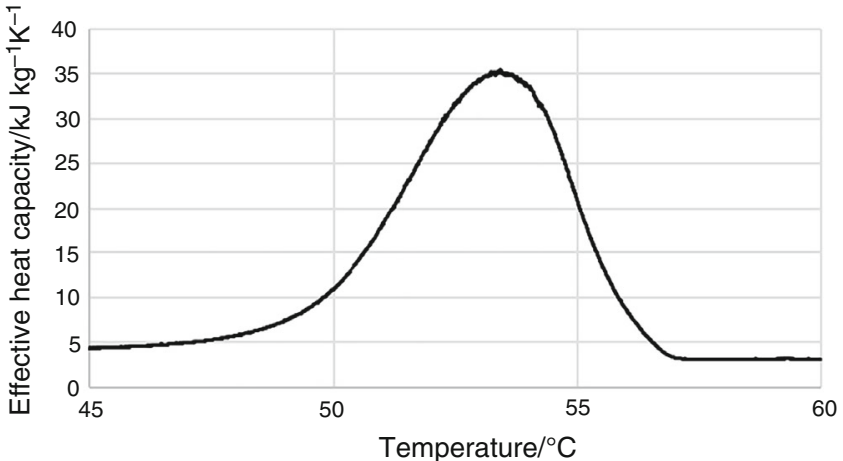

It is less accurate, but the computation demand of this model is much lower.

An example is shown in Fig. 4. The temperature-effective heat capacity results are similar to Model I presented, but as a difference this model is optimized for the temperature-enthalpy line. In Model I, effective enthalpy is fitted in the range of melting and the integrated graph chart shows a line with a slope. Model IV optimizes the slope of the integrated graph first, and the temperature-heat capacity graph is generated afterwards.

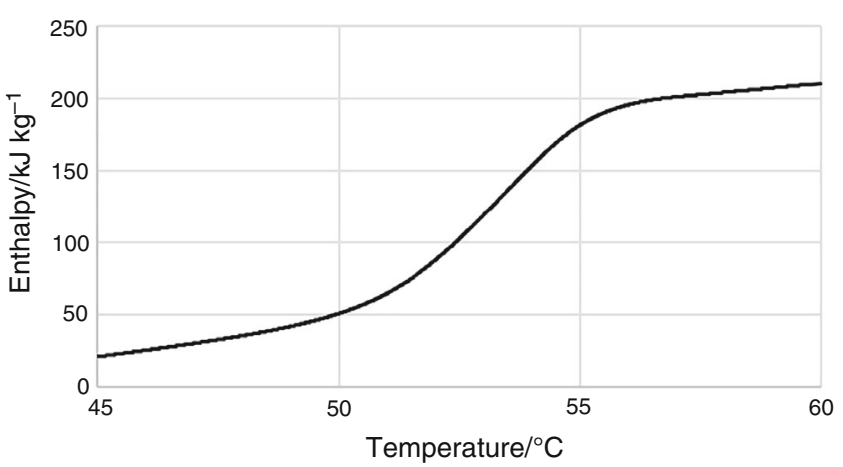

Fig. 3 Temperature-effective heat capacity and temperature-enthalpy curves for enthalpy method for P53 

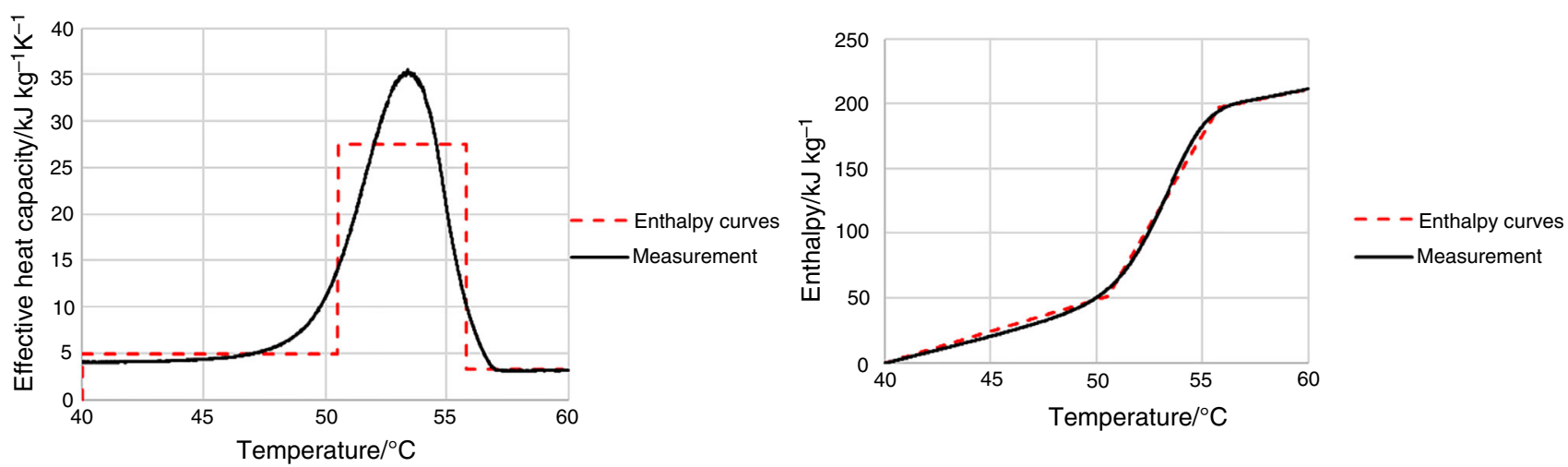

Fig. 4 Temperature-effective heat capacity and temperature-enthalpy lines for the enthalpy method with fitted lines

Table 2 Summary of the models and their describing factors

\begin{tabular}{ll}
\hline Model & Describing factors \\
\hline I & $c_{\mathrm{s}}, c_{1}, L_{\mathrm{f}}, T_{\mathrm{m}}, \Delta T_{\mathrm{m}}$ \\
II & $c_{\mathrm{s}}, c_{1}, L_{\mathrm{f}}, T_{\mathrm{s}}^{\mathrm{m}}, T_{1}^{\mathrm{m}}, T_{\mathrm{m}}$ \\
& $c_{\mathrm{s}}, c_{\mathrm{l}}, T_{\mathrm{s}}^{\mathrm{m}}, T_{1}^{\mathrm{m}}, T_{\mathrm{m}}$, line1, line2 \\
III & Temperature-enthalpy data pairs \\
IV & $c_{\mathrm{s}}, c_{1}, L_{\mathrm{f}}, T_{\mathrm{s}}^{\mathrm{m}}, T_{1}^{\mathrm{m}}$ \\
& $c_{\mathrm{s}}, c_{1}, T_{\mathrm{s}}^{\mathrm{m}}, T_{1}^{\mathrm{m}}$, line1 \\
& line1, line2, line3 \\
\hline
\end{tabular}

This model has high accuracy with a low computation demand.

Table 2 presents the previously described models and their describing factors. These factors are needed to investigate the thermal behaviour of PCMs with each model. In Model II and IV, the multiple rows show alternative options, i.e. it is possible to use equations of the lines calculated earlier.

\section{Modelling the interrupted phase change}

Hysteresis is the temperature difference between the melting and solidification temperature of the respective melting and solidification curve. Researchers use different ways to model the hysteresis and the two-phase state.

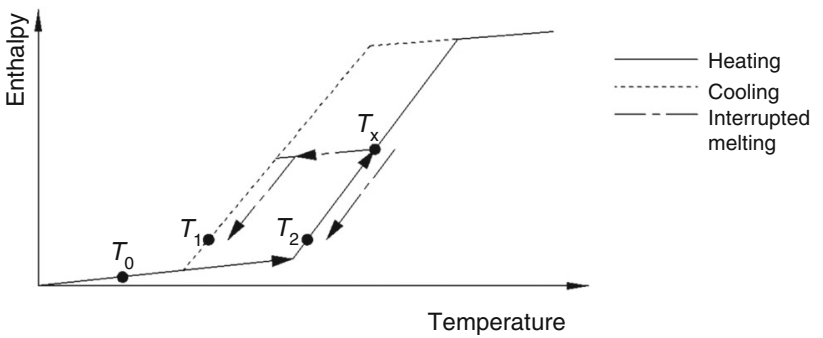

Fig. 5 Usual models for PCM behaviour when melting is interrupted and the PCM is cooled back
Figure 5 presents a hysteresis of a material. The material is heated from point $T_{0}$ to point $T_{\mathrm{x}}$, where heating and melting are interrupted and cooling is started. There are two different scenarios which materials may follow:

- The 'Transition scenario' (TS), suggested by Bony and Citherlet [24], is a transition to the cooling curve using a slope equivalent to the solid or liquid specific heat; in this case, the end point is at point $T_{1}$,

- The 'Stay scenario' (SS), in which Chandrasekharan et al. [25] have suggested another option, consists of staying on the heating curve to reach point $T_{2}$.

As the scenarios based on the literature show a different approach in modelling the two-phase state of a material, it should be decided which model is to be used in which case for the highest accuracy or whether there is a need for a new model. The aim of this paper is to evaluate the accuracy of the presented two-phase scenarios.

The research presented in [34] is addressing the same problem, and their results show quite different behaviour of the investigated process. The authors demonstrate an optimization model, which can calculate the interrupted phase change process. According to their model, the interrupted phase change follows an enthalpy curve which is located between the heating and cooling curves. The article does not describe their optimization algorithm in detail, so it was not possible to compare our results with their models.

\section{Methods}

The calorimetry measurements were taken with a TA DSC Q2000 device with a temperature accuracy of $\pm 0.1{ }^{\circ} \mathrm{C}$. It measures the difference in the heat flow rate between a sample and inert reference as a function of time and temperature. The temperature was measured at the sample 
platform with a thermocouple. The sample sizes were between 5 and $10 \mathrm{mg}$ and were encapsulated with Tzero Pans (container of the sample material) and Lids (cap of the container).

$\frac{\mathrm{d} H}{\mathrm{~d} t}=c_{\mathrm{p}} \cdot m \cdot \frac{\mathrm{d} T}{\mathrm{~d} t}+f(T, t)$

With Eq. 3 the effective specific heat capacity could be calculated, where $f(T, t)$ is the heat flow that is a function of time at an absolute temperature. The $f$-function describes the kinetic behaviour of the samples, which defines the kinetic dependency and the non-equilibrium character that associates with nonlinear features of the transition, and is highly dependent on the heating/cooling rates. In this case it can be omitted, because we used the same heating/cooling rates. We did not aim to investigate the kinetic effects of the materials, and we developed a model to describe the two-phase state for a material with known hysteresis corner points.

Three different samples were measured three times with $0.5 \mathrm{~K} \mathrm{~min}^{-1}$ heating/cooling rate, and the presented results show the average of the measurements. The aim was to determine the behaviour of materials in the solid-liquid two-phase state. Researchers use different models, and the measurements have to determine which model is the most accurate to use for which case.

Based on earlier measurements carried out on the presented P53 [35], the full melting range is between 50.5 and $56.5^{\circ} \mathrm{C}$. Interrupted melting was measured in cycles with a minimum temperature of $40{ }^{\circ} \mathrm{C}$ and a maximum temperature of 50.9, 51.8, 52.7, 53.9, 54.9, 55.8 ${ }^{\circ} \mathrm{C}$ (signed with Melting 1-6). The maximum temperature points equally divide the heating curve in the mean of enthalpy.

The interrupted solidification of the P53 was investigated in the following temperature points: 54.3, 53.4, 52.4, $51.35,50.3{ }^{\circ} \mathrm{C}$ (signed with Solidification 1-5), and these points also equally divide the cooling curve.
The modelling was carried out in MATLAB R2016A software.

\section{Results and discussion}

The measurements of full cycles of melting and solidification on P53 material are presented in Fig. 6. The black curve shows the process of melting, and the blue one shows that of solidification. 3-3 lines (shown with dashed lines) were fitted to these curves with the use of Model IV to get the most accurate approximation. The fully solid and liquid state lines are equal, so it is possible to model the full phase change cycle with four lines. Figure 7 shows the full cycle and the fitted lines for the C.oil20 material.

Figure 8 shows the much wider hysteresis of C.oil20. The P53 hysteresis is located on a higher temperature range; however, for the purpose of demonstrating the great difference between the hysteresis of the two investigated materials, the width of the P53 hysteresis is shown with dashed lines transposed on the fitted temperature lines of C.oil20 hysteresis.

The presented Model IV was developed for the melting and solidification, and the curve fitting algorithm was optimized for P53 with small hysteresis $\left(0.8-1{ }^{\circ} \mathrm{C}\right.$ difference between the melting and solidification curves) and tested on C.oil 20 with huge hysteresis $\left(5-10.5^{\circ} \mathrm{C}\right.$ difference). Table 3 shows the corner points of the hysteresis for the investigated materials. These points are the results of the optimization described in Model IV and focus on the highest accuracy.

The second step was the measurement of interrupted phase changes. Figures 9 and 10 present the temperatureheat flow curves for the interrupted melting and solidification respectively, measured with a TA DSC Q2000 device. These curves show the heat requirement to raise the temperature of $1 \mathrm{~g}$ of material by unit temperature interval for different interruption temperatures (described in the
Fig. 6 Full measurement cycle for the P53 and the fitted lines

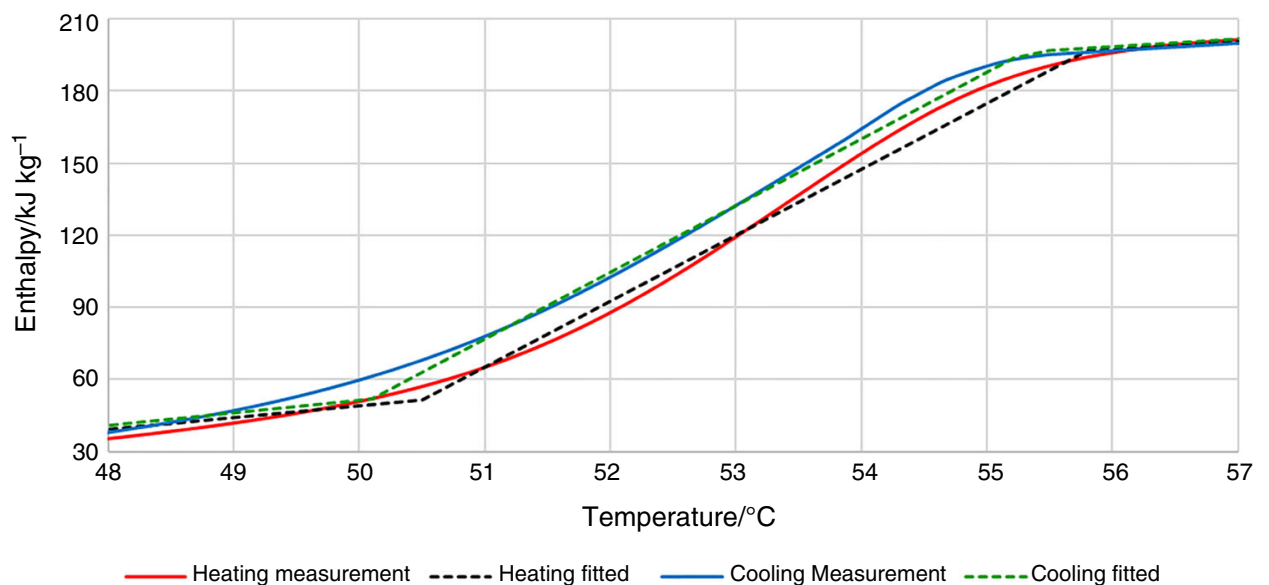




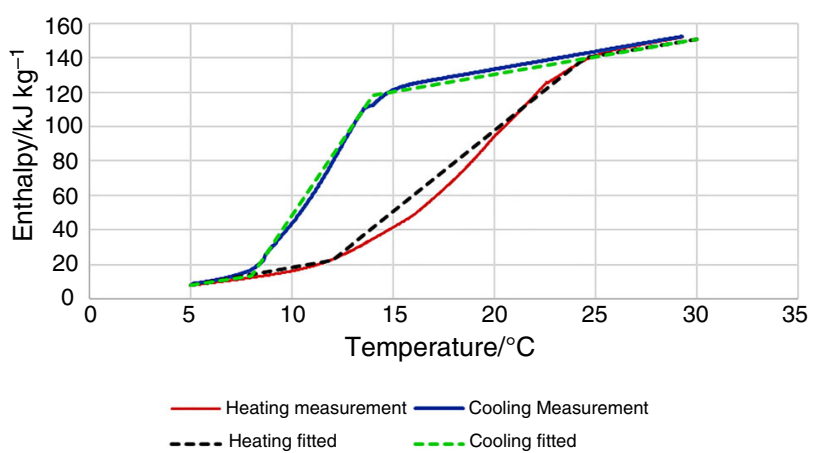

Fig. 7 Full measurement cycle for C.oil20 and the fitted lines

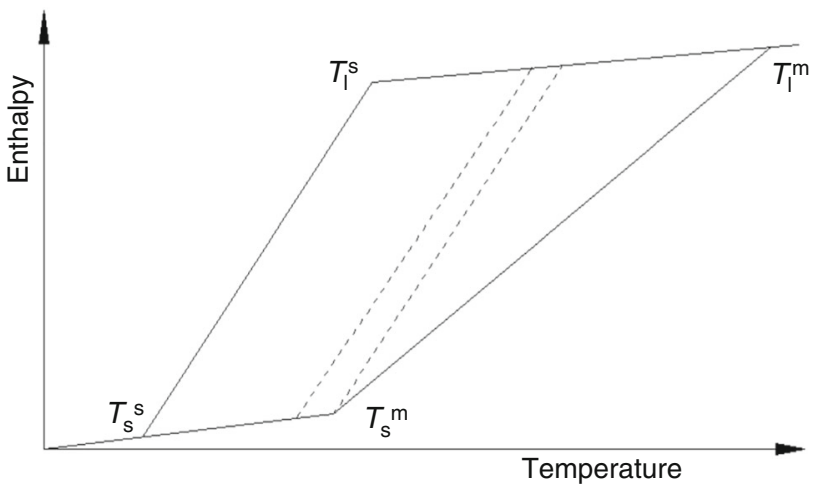

Fig. 8 C.oil20 hysteresis and the transposed paraffin hysteresis dashed as a reference (see the corner points in Table 3)

Table 3 Physical properties of the used PCMs

\begin{tabular}{lll}
\hline & P53 & C.oil20 \\
\hline$T_{\mathrm{s}}^{\mathrm{m}}$-Beginning temperature of melting $/{ }^{\circ} \mathrm{C}$ & 50.5 & 13 \\
$T_{1}^{\mathrm{m}}$-End temperature of melting $/{ }^{\circ} \mathrm{C}$ & 56.5 & 24.5 \\
$T_{\mathrm{s}}^{\mathrm{s}}$ - end temperature of solidification $/{ }^{\circ} \mathrm{C}$ & 49.5 & 8 \\
$T_{1}^{\mathrm{s}}$-Beginning temperature of solidification $/{ }^{\circ} \mathrm{C}$ & 55.7 & 14 \\
\hline
\end{tabular}

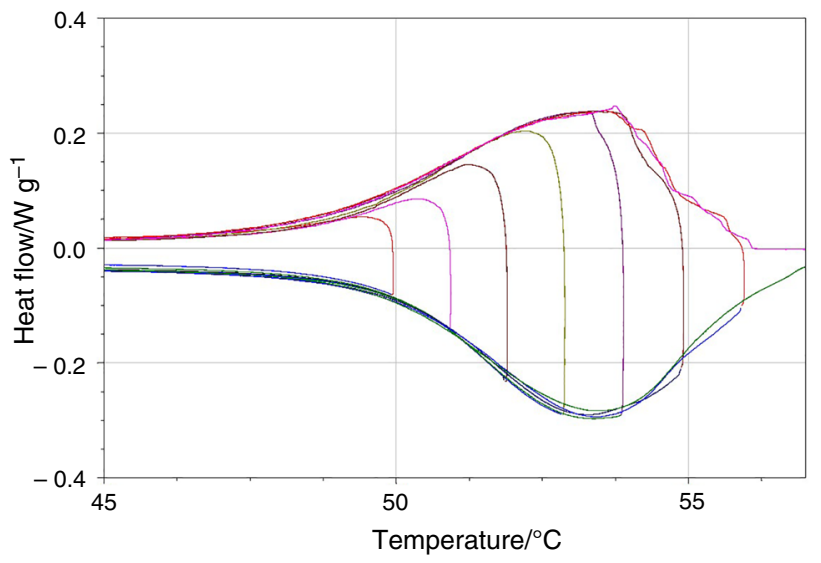

Fig. 9 Interrupted melting of P53, temperature-heat flow graph

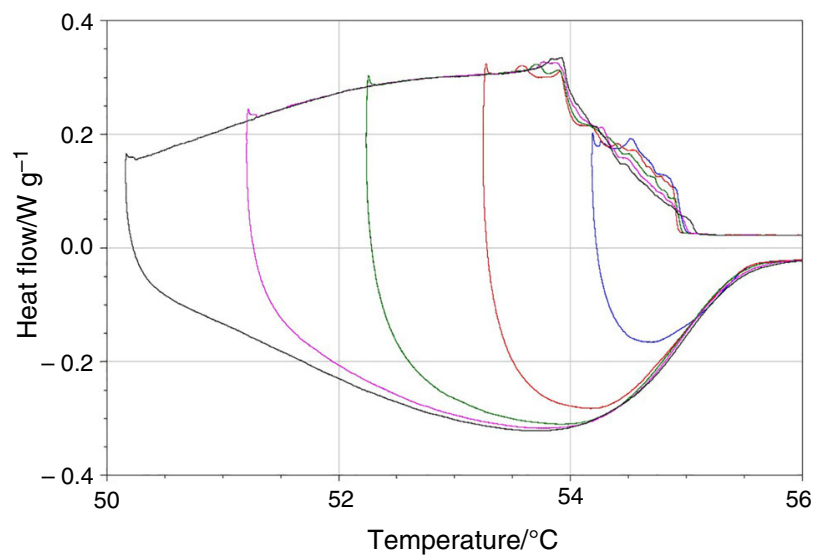

Fig. 10 Interrupted solidification of P53, temperature-heat flow graph

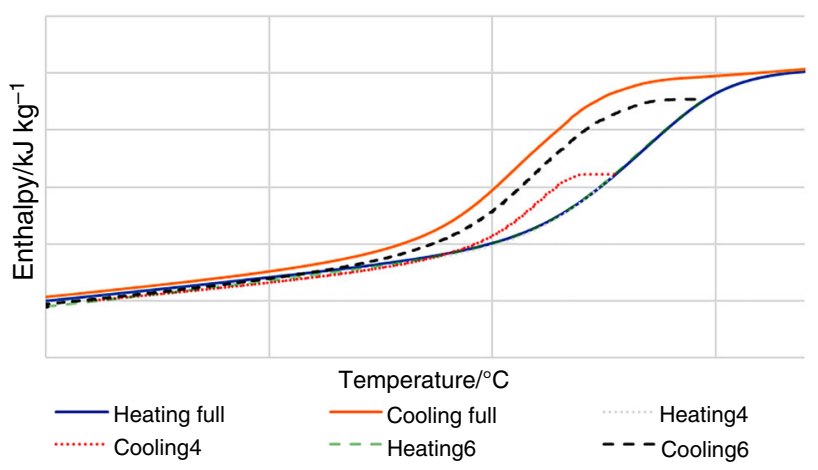

Fig. 11 Interrupted melting of P53, temperature-enthalpy graph

Methods). The evaluation was carried out with a TA Universal Analysis 2000 software. After the interruption, the cooling/heating curves show a different behaviour than the melting or solidification curve, so the presented twophase models will not be correct for the investigated P53. A new model is needed to ensure the accurate simulations of phase change materials.

Figure 11 shows the interrupted melting of paraffin in the temperature-enthalpy plane. The melting was interrupted at the temperature points of 52.7 and 54.9. The results show that the material does not stay on the heating curve and is not transitioned to the cooling curve, but it remains between the heating and cooling curves and has a shape similar to the cooling curve. If the interruption occurs later, when the temperature and liquid fraction are higher in the P53, the curve showing the interruption is closer to the cooling curve. Modelling with the TS [24] is more accurate when the interruption occurs at higher liquid fraction, while the SS [25] works in another way, i.e. it is more accurate when the interruption occurs earlier.

According to data from the phase change interruption measurements, the two-phase state behaviour could be modelled with two fitted lines. The break or corner points 


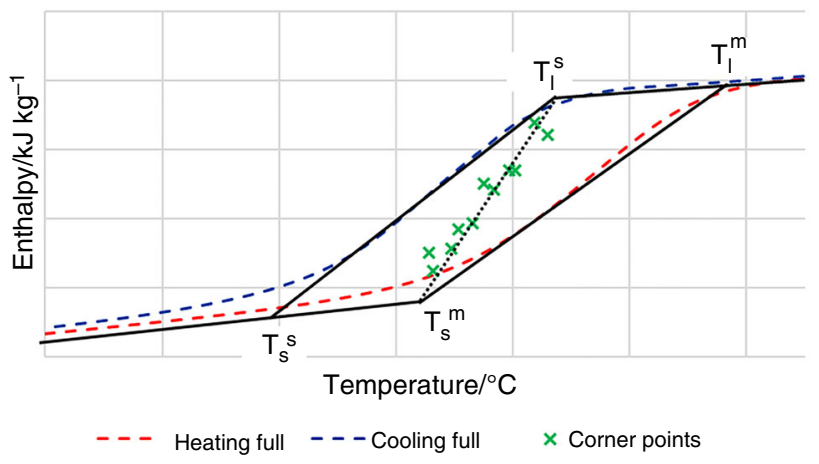

Fig. 12 Corner points fitting

of these two lines are presented in Fig. 12. By using the diagonal of the hysteresis connecting points $T_{\mathrm{s}}^{\mathrm{m}}$ and $T_{1}^{\mathrm{s}}$ as a fitted line, $R^{2}$ is 0.965 . Not only does it make the modelling simpler and quicker, but it also gives an easy aspect on how to implement and calculate the two-state model with new materials. The computation requirements are low, and the model can easily be used for all points of the hysteresis and not only for the measured points, as if a database were used. For easier reference, the developed model will be referred as 'diagonal model'.

Basically, $f$, the liquid fraction of the PCM, is calculated with the use of the enthalpy difference, but due to the linearization, it could be calculated with the temperature difference:
$f_{\mathrm{x}}^{\mathrm{m}}=\frac{\left(H_{\mathrm{x}}^{\mathrm{m}}-H_{\mathrm{s}}^{\mathrm{m}}\right)}{\left(H_{1}^{\mathrm{m}}-H_{\mathrm{s}}^{\mathrm{m}}\right)}=\frac{\left(T_{\mathrm{x}}^{\mathrm{m}}-T_{\mathrm{s}}^{\mathrm{m}}\right)}{\left(T_{1}^{\mathrm{m}}-T_{\mathrm{s}}^{\mathrm{m}}\right)}$

$f_{\mathrm{x}}^{\mathrm{s}}=\frac{\left(H_{\mathrm{x}}^{\mathrm{s}}-H_{\mathrm{s}}^{\mathrm{s}}\right)}{\left(H_{1}^{\mathrm{s}}-H_{\mathrm{s}}^{\mathrm{s}}\right)}=\frac{\left(T_{\mathrm{x}}^{\mathrm{s}}-T_{\mathrm{s}}^{\mathrm{s}}\right)}{\left(T_{1}^{\mathrm{s}}-T_{\mathrm{s}}^{\mathrm{s}}\right)}$

The line fitting algorithm for the interrupted melting uses the liquid fraction, which defines the unknown temperature-enthalpy points in the two-state phase diagram. The liquid fraction also could be calculated with the use of the same enthalpy points.

$f_{\mathrm{x}}^{\mathrm{m}}=\frac{\left(T_{\mathrm{x}}^{\mathrm{m}}-T_{\mathrm{s}}^{\mathrm{m}}\right)}{\left(T_{1}^{\mathrm{m}}-T_{\mathrm{s}}^{\mathrm{m}}\right)}=\frac{\left(T_{\mathrm{x}}^{\mathrm{c}}-T_{\mathrm{s}}^{\mathrm{m}}\right)}{\left(T_{1}^{\mathrm{s}}-T_{\mathrm{s}}^{\mathrm{m}}\right)}=\frac{\left(T_{\mathrm{s}}^{\mathrm{m}}-T_{\mathrm{s}, \mathrm{x}}^{\mathrm{c}}\right)}{\left(T_{\mathrm{s}}^{\mathrm{m}}-T_{\mathrm{s}}^{\mathrm{s}}\right)}$

Points $T_{\mathrm{x}}^{\mathrm{c}}$ and $T_{\mathrm{s}, \mathrm{x}}^{\mathrm{c}}$ are defined in Fig. 13a.

As temperature is an irrespective variable, calculations should be made for the enthalpy of corner points; and as some of the PCM simulations calculate with enthalpy, equations to calculate the temperature for enthalpy are also necessary.For the interrupted solidification, the line fitting uses the following equations:

$f_{\mathrm{x}}^{\mathrm{s}}=\frac{\left(T_{\mathrm{x}}^{\mathrm{s}}-T_{\mathrm{s}}^{\mathrm{s}}\right)}{\left(T_{\mathrm{l}}^{\mathrm{s}}-T_{\mathrm{s}}^{\mathrm{s}}\right)}=\frac{\left(T_{\mathrm{x}}^{\mathrm{c}}-T_{\mathrm{s}}^{\mathrm{m}}\right)}{\left(T_{1}^{\mathrm{s}}-T_{\mathrm{s}}^{\mathrm{m}}\right)}=\frac{\left(T_{1}^{\mathrm{m}}-T_{1, \mathrm{x}}^{\mathrm{c}}\right)}{\left(T_{1}^{\mathrm{m}}-T_{1}^{\mathrm{s}}\right)}$

$T_{\mathrm{x}}^{\mathrm{c}}$ and $T_{1, \mathrm{x}}^{\mathrm{c}}$ are shown in Fig. $13 \mathrm{~b}$.
Fig. 13 Interrupted phase change and two-phase state modelling: a interrupted melting and $\mathbf{b}$ interrupted solidification
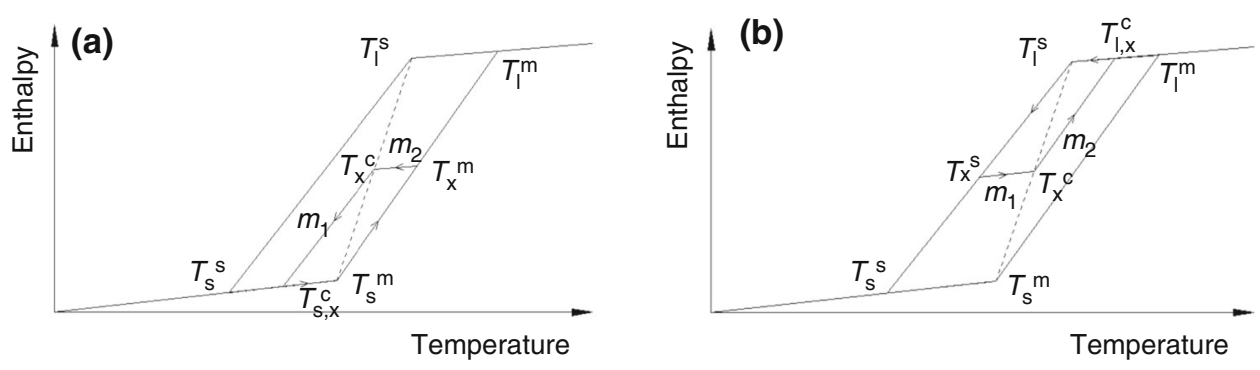

Table $4 \mathrm{R}^{2}$ values comparing the measurement with different models for P53

\begin{tabular}{llllll}
\hline & $T_{\mathrm{x}}{ }^{\circ} \mathrm{C}$ & $H_{\mathrm{x}} / \mathrm{kJ} \mathrm{kg}^{-1}$ & $\mathrm{SS} / \%$ & $\mathrm{TS} / \%$ & Diagonal model/\% \\
\hline Heating full & - & - & 0.998 & 0.983 & - \\
Cooling full & - & - & 0.982 & 0.998 & - \\
Melting 1 & 50.9 & 16.7 & 0.979 & 0.943 & 0.989 \\
Melting 2 & 51.8 & 33.3 & 0.976 & 0.961 & 0.992 \\
Melting 3 & 52.7 & 69.2 & 0.973 & 0.963 & 0.995 \\
Melting 4 & 53.9 & 121.2 & 0.967 & 0.967 & 0.996 \\
Melting 5 & 54.9 & 160.3 & 0.965 & 0.971 & 0.997 \\
Melting 6 & 55.8 & 183.4 & 0.956 & 0.973 & 0.998 \\
Solidification 1 & 54.3 & 166.7 & 0.957 & 0.990 & 0.998 \\
Solidification 2 & 53.4 & 126.5 & 0.962 & 0.987 & 0.998 \\
Solidification 3 & 52.4 & 84.1 & 0.965 & 0.982 & 0.996 \\
Solidification 4 & 51.35 & 45.2 & 0.971 & 0.981 & 0.995 \\
Solidification 5 & 50.3 & 16.2 & 0.972 & 0.978 & 0.993 \\
\hline
\end{tabular}


Lines were fitted to describe the two-phase process more accurately.

Table 4 shows $R^{2}$ values when the results of Model IV were compared to measurements.

The SS column shows the value of $R^{2}$ when the modelling was based on the two-phase model SS. This also applies for the TS column. The diagonal model shows the model that was developed for the accurate simulation.

In Table $4 R^{2}$ gets lower with the SS modelling when the temperature is getting higher and the use of the TS model gets more accurate. This can also be seen concerning the interrupted solidification.

As mentioned above, the diagonal model was developed using the measurement data of P53 interrupted phase change and was also tested for C.oil20. The results for coconut butter show a good relation with the theory shown above. The $R^{2}$ for measurements of C.oil20 is presented in Table 5. The results look similar.

Tables 4 and 5 present the accuracy of the different twophase scenarios. At higher temperatures, the TS (interrupted phase change using the cooling curve) is more accurate, while on the other hand, at lower temperatures the certainty of the SS (material uses the heating curve after an interruption in phase change) is higher. The diagonal model has the highest accuracy for all measured points.

The results in Tables 4 and 5 show the accuracy of diagonal model on interrupted phase change with $0.5 \mathrm{~K} \mathrm{~min}^{-1}$ heating/cooling rate. According to our results, the diagonal model probably can be used for arbitrary heating/cooling rates as well. Table 6 presents the accuracy on the simulations of P53 material when the DSC measurements were taken with $2 \mathrm{~K} \mathrm{~min}^{-1}$ heating/cooling rate. Similar results can be seen as in Tables 4 and 5, so the model is not dependent on the DSC heating/cooling rate. The results of the diagonal model are more accurate for both heating/cooling rates than the investigated TS and SS models.

\section{Conclusions and further research aims}

This paper presents a new method to model the thermal behaviour of materials in the solid-liquid two-phase state. Measurements were taken with a DSC TA Q2000 device on P53 paraffin and C.oil20 coconut oil for full phase change and for interruption in melting and solidification. Four existing models were presented, and their accuracy was investigated.

Two different scenarios were taken from the literature and investigated to model the thermal behaviour of materials in the solid-liquid two-phase state when an interrupted phase change occurs. The new diagonal model was established evaluating the measurements of the investigated P53 paraffin wax material and was tested for the C.oil20 coconut oil. According to the measurements, the interrupted phase change could be modelled accurately with fitting two lines, where the corner points of the lines are located near the $T_{\mathrm{s}}^{\mathrm{m}}-T_{1}^{s}$ diagonal of the hysteresis. Modelling accuracy was highly increased, which means a more accurate simulation of phase change material
Table $5 \mathrm{R}^{2}$ values comparing the measurement with different models for C.oil20

Table $6 \mathrm{R}^{2}$ values comparing the measurement with different models for P53 with $2 \mathrm{~K} \mathrm{~min}^{-1}$ heating/cooling rate

\begin{tabular}{llllll}
\hline & $T_{\mathrm{x}} /{ }^{\circ} \mathrm{C}$ & $H_{\mathrm{x}} / \mathrm{kJ} \mathrm{kg}^{-1}$ & $\mathrm{SS} / \%$ & $\mathrm{TS} / \%$ & Diagonal model/\% \\
\hline Heating full & - & - & 0.997 & 0.714 & - \\
Cooling full & - & - & 0.738 & 0.998 & - \\
Melting 1 & 15.3 & 37.55 & 0.951 & 0.718 & 0.991 \\
Melting 2 & 19.25 & 75 & 0.894 & 0.798 & 0.984 \\
Melting 3 & 23.09 & 127.2 & 0.791 & 0.885 & 0.986 \\
Solidification 1 & 13.35 & 101.3 & 0.80 & 0.942 & 0.989 \\
Solidification 2 & 12 & 76 & 0.911 & 0.881 & 0.985 \\
Solidification 3 & 9.5 & 41.6 & 0.926 & 0.789 & 0.982 \\
\hline
\end{tabular}

\begin{tabular}{llllll}
\hline & $T_{\mathrm{x}} /{ }^{\circ} \mathrm{C}$ & $H_{\mathrm{x}} / \mathrm{kJ} \mathrm{kg}^{-1}$ & $\mathrm{SS} / \%$ & $\mathrm{TS} / \%$ & Diagonal model/\% \\
\hline Heating full & - & - & 0.993 & 0.987 & \\
Cooling full & - & - & 0.985 & 0.991 & \\
Melting 1 & 51 & 15.4 & 0.982 & 0.951 & 0.989 \\
Melting 2 & 53 & 74.6 & 0.975 & 0.966 & 0.995 \\
Melting 3 & 55 & 154.7 & 0.968 & 0.973 & 0.997 \\
Solidification 1 & 54.5 & 166.7 & 0.961 & 0.992 & 0.998 \\
Solidification 2 & 52.5 & 89.8 & 0.968 & 0.986 & 0.996 \\
Solidification 3 & 50 & 16.2 & 0.977 & 0.970 & 0.993 \\
\hline
\end{tabular}


applications. The results of the model show high accuracy for the two investigated materials and for the different heating/cooling rates.

After further research, results can be extended to all paraffin waxes and also for fatty acids due to their similar chemical structure. Further research will be aimed at investigating the interrupted phase change with a higher resolution, with more interruption points in the melting and solidification process. Furthermore, the accuracy of the model should be investigated if the fitted lines in the interrupted lines were calculated from the liquid fraction of the PCM.

Acknowledgements Open access funding provided by Budapest University of Technology and Economics (BME). The DSC measurements were taken with the help of the Department of Polymer Engineering, Budapest University of Technology and Economics.

Open Access This article is distributed under the terms of the Creative Commons Attribution 4.0 International License (http://creative commons.org/licenses/by/4.0/), which permits unrestricted use, distribution, and reproduction in any medium, provided you give appropriate credit to the original author(s) and the source, provide a link to the Creative Commons license, and indicate if changes were made.

Funding The measurements were supported by Balázs Pinke and the Department of Polymer Engineering at Budapest University of Technology and Economics. This study was supported by the ÚNKP17-3 New National Excellence Program of the Ministry of Human Capacities. The research reported in this paper was supported by the Higher Education Excellence Program of the Ministry of Human Capacities in the frame of Water science \& Disaster Prevention research area of Budapest University of Technology and Economics (BME FIKP-MI).

\section{References}

1. Alibakhsh K, Leyli B, Fathollah P, Erfan K, Wei-Mon Y. Experimental studies on the applications of PCMs and nanoPCMs in buildings: a critical review. Energy Build. 2017;154:96-112.

2. Venkateswara RV, Parameshwaran R, Vinayaka RV. PCMmortar based construction materials for energy efficient buildings: a review on research trends. Energy Build. 2018;158:95-122.

3. Guarino F, Dermardiros V, Chen Y, Rao J, Athienitis A, Cellura M, Mistretta M. PCM thermal energy storage in buildings: experimental study and applications. Energy Procedia. 2015;70:219-28.

4. Memon SA, Liao W, Yang S, Cui H, Shah SFA. Development of composite PCMs by incorporation of paraffin into various building materials. Materials. 2015;6:499-518.

5. Reza B, John JJC, Brent RY, Mohammed MF. Application of PCM underfloor heating in combination with PCM wallboards for space heating using price based control system. Appl Energy. 2015;148:39-48.

6. Dan S, Lijiu W. Utilization of paraffin/expanded perlite materials to improve mechanical and thermal properties of cement mortar. Constr Build Mater. 2015;101:791-6.
7. Mayer MJ. Comparison of different solar energy utilization methods: Photovoltaic systems and solar thermal power plants. In: 5th international youth conference on energy, 2015.

8. Pere M, Albert C, Cristian S, Gabriel Z, Luisa FC. PCM thermal energy storage tanks in heat pump system for space cooling. Energy Build. 2014;82:399-405.

9. Oró E, de Gracia A, Castell A, Farid MM, Cabeza LF. Review on phase change materials (PCMs) for cold thermal energy storage applications. Appl Energy. 2012;99:513-33.

10. Ana L, Conchita P, Aran S, Gonzalo D, Thomas H, Magali F, Belén Z, Stefan G, Luisa FC. Intercomparative tests on phase change materials characterisation with differential scanning calorimeter. Appl Energy. 2013;109:415-20.

11. Kevin M, Didier D, Jérôme S, Luc T. Heat transfer enhancement in latent heat thermal storage systems: comparative study of different solutions and thermal contact investigation between the exchanger and the PCM. Appl Energy. 2016;166:107-16.

12. Xing J, Huoyan H, Xing S, Xin Z, Liu Y, Yonggao Y, Xiaosong $Z$. A new heat transfer model of phase change material based on energy asymmetry. Appl Energy. 2018;212:1409-16.

13. Eva G, Stefan H, Harald M, Robert R. Enthalpy of phase change materials as a function of temperature: required accuracy and suitable measurement methods. Int $\mathrm{J}$ Thermophys. 2009;30:1257-69.

14. Tsilingiris PT. Parametric space distribution effects of wall heat capacity and thermal resistance on the dynamic thermal behavior of walls and structures. Energy Build. 2006;38:1200-11.

15. Shuli L, Muriel I, Ashish S. Numerical study on the performance of an air-multiple PCMs unit for free cooling and ventilation. Energy Build. 2017;151:520-33.

16. Mactar F, Berangere L, Vincent S. A new procedure for the experimental measurement of the effective heat capacity of wall elements. Energy Build. 2015;103:62-9.

17. Mandilaras ID, Kontogeorgos DA, Founti MA. A hybrid methodology for the determination of the effective heat capacity of PCM enhanced building components. Renew Energy. 2015;76:790-804.

18. Xing J, Huoyan H, Xing S, Xin Z, Xiaosong Z. Comparison of two numerical heat transfer models for phase change material board. Appl Therm Eng. 2018;128:1331-9.

19. Kaushik B, Jue L, Parviz S, Som S. Combined experimental and numerical evaluation of a prototype nano-PCM enhanced wallboard. Appl Energy. 2014;131:517-29.

20. Eric T, Cho LC, Peiwen L, Ben X. An enthalpy formulation for thermocline with encapsulated PCM thermal storage and benchmark solution using the method of characteristics. Int J Heat Mass Transf. 2014;79:362-77.

21. Xing J, Mario AM, Xiaosong Z. Numerical analysis for the optimal location of a thin PCM layer in frame walls. Appl Therm Eng. 2016;103:1057-63.

22. Alexander MT, Gaurav S, Laurent P. Diurnal thermal analysis of microencapsulated PCM-concrete composite walls. Energy Convers Manag. 2015;93:215-27.

23. Frédéric K, Joseph V, Jean-Jacques R. Energetic efficiency of room wall containing PCM wallboard: a full-scale experimental investigation. Energy Build. 2008;40:148-56.

24. Bony J, Citherlet S. Numerical model and experimental validation of heat storage with phase change materials. Energy Build. 2007;39:1065-72.

25. Chandrasekharan R, Lee ES, Fisher DE, Deokar PS. An enhanced simulation model for building envelopes with phase change materials. ASHRAE Trans. 2013;119:1-10.

26. Arkar C, Medved S. Influence of accuracy of thermal property data of a phase change material on the result of a numerical model of a packed bed latent heat storage with spheres. Thermochim Acta. 2005;438:192-201. 
27. Pishchur DP, Drebushchak VA. Recommendations on DSC calibration. J Therm Anal Calorim. 2016;124:951-8.

28. Akihiko T. Heating rate dependence of melting peak temperature examined by DSC of heat flux type. J Therm Anal Calorim. 2016;123:1795-808.

29. Betül SS, Hasan N, Erdal E, Orhan A, Sevi Ö. Thermal kinetic analysis, theoretical thermodynamic calculations and antimicrobial activity of three new energetic materials. J Therm Anal Calorim. 2018;131:3105-20.

30. Mehedi BM, Geoffrey AB, Muhammad AR. Premelting, melting, and degradation properties of molten alkali nitrates: $\mathrm{LiNO}_{3}$, $\mathrm{NaNO}_{3}, \mathrm{KNO}_{3}$, and Binary $\mathrm{NaNO}_{3}-\mathrm{KNO}_{3}$. Metall Mater Trans B. 2018;49:1482-98.

31. Camila B, Aran S, Laia M, Ingrid M, Inés FA, Luisa FC. Study on differential scanning calorimetry analysis with two operation modes and organic and inorganic phase change material (PCM). Thermochim Acta. 2013;553:23-6.
32. Bo H, Viktoria M, Fredrik S. Phase transition temperature ranges and storage density of paraffin wax phase change materials. Energy. 2004;29:1785-804.

33. Feng G, Huang K, Xie H, Li H, Liu X, Liu S, Cao C. DSC test error of phase change material (PCM) and its influence on the simulation of the PCM floor. Renew Energy. 2016;87:1148-53.

34. Benoit D, Michaël K, Ahmed D. Thermal behaviour mapping of a phase change material between the heating and cooling enthalpytemperature curves. Energy Procedia. 2015;78:225-30.

35. Zoltán A, Sz Zoltán. Modelling of latent thermal energy storage systems. Int Rev Appl Sci Eng. 2017;8:51-6.

Publisher's Note Springer Nature remains neutral with regard to jurisdictional claims in published maps and institutional affiliations. 